\title{
Negative Sequence Voltage Magnitude based Unsynchronized Fault Location on Three Terminal Lines
}

\author{
Anuradha Amireddy ${ }^{1}$, Kishore Kumar Pedapenki ${ }^{2}$ \\ Associate Professor, EEE, VIIT, Visakhapatnam, India ${ }^{1}$ \\ M.Tech. Student, EEE, VIIT, Visakhapatnam, India ${ }^{2}$
}

\begin{abstract}
Accurate fault locating on transmission lines is of great value to the power transmission operators. Most micro-processor based relays implement fault location using different impedance based methods. This paper describes an approach for the estimation of fault based on negative sequence voltage magnitude at both ends of the faulted circuit. A two-ended fault location method is used for estimating the fault distance measurement accuracy by using the data of two ends of the line to revoke the effect of fault resistance \& mutual coupling between the negative sequence components of the two circuits since negative sequence circuit is considered. The two-ended method locates the unsymmetrical faults independent of fault classification \& pre-fault conditions. Study of this work can be analysed using unsynchronized fault location for three terminal lines. Based on unsynchronized measurements, fault estimation is tested for different cases. Fault location will be modelled using lumped parameter \& PI model \& is implemented in MATLAB environment.
\end{abstract}

Keywords: Negative Sequence Voltage Magnitude, one end and two end methods, Impedance Measurements, Fault Location.

\section{INTRODUCTION}

There are different types of methodologies that are used for estimating fault location in transmission lines based on negative sequence voltages and unsynchronized measurements [10]. Fault location techniques can be generally classified into the following main categories:

- Based on fundamental-frequency currents and voltages, mainly on impedance measurement

- Based on travelling-wave phenomenon

- Knowledge-based approaches

- Based on high-frequency components of currents and voltages generated by fault

The present used Fault Locating Algorithm is of Impedance-based algorithm which if further classified as one-end \& two-end based algorithms which makes use of the line parameters (such as resistance, inductance and conductance per unit length, and the line length) as well as voltage and current data from one or more line terminals to calculate the distance to the fault from a reference point or line terminal [1] [2] ; whether they are for single-circuit or double-circuit transmission lines. Two-ended fault location estimation is fundamentally similar to the one-terminal algorithm but can improve the accuracy of fault distance measurements significantly by using data from the two ends of the line to cancel the effect of fault resistance and in feed [2].Two end and multi-end fault location algorithms divided in two main categories, unsynchronized and synchronized measurements. The algorithms process signals from both terminals of the line and a large amount of information is utilized. Therefore, performance of the two-end algorithm is generally superior in comparison to the one-end approaches.

\section{PROBLEM FORMULATION}

The two-ended fault location method is a new fault-location method for double-circuit transmission lines using the magnitudes of negative-sequence voltages measured at both ends of the faulted circuit. The faulted circuit is assumed to be known based on distance relays action and circuit-breaker (CB) status. In this method, fault classification is not required to estimate fault location which is a specific feature in comparison to the fault locators that need to first classify the fault type. One interesting attribute of the proposed method is that the fault-location accuracy still remains high for long transmission lines even when the lumped model is employed since the proposed method uses only the voltage data and the ratio between voltages of both ends. Moreover, the method is fully analytical even when the shunt 
UGC Approved Journal

IJIREEICE

\section{International Journal of Innovative Research in} Electrical, Electronics, Instrumentation and Control Engineering

\section{ISO 3297:2007 Certified}

Vol. 5, Issue 7, July 2017

capacitances are considered. The accuracy of the method, together with its practicality, makes it an attractive option to implement in the relays as a fault-location function.

\section{TWO-ENDED NEGATIVE SEQUENCE IMPEDANCE METHOD}

The system under study is a $400-\mathrm{kV}, 50-\mathrm{Hz}$ double-circuit transmission line of 200-km length. Protection of Doublecircuit transmission lines is done by using distance relays of sending and receiving ends. The negative sequence quantities from all line terminals are used for locating unbalanced faults to negate the effect of pre-fault load, fault resistance \& zero sequence mutual impedance.

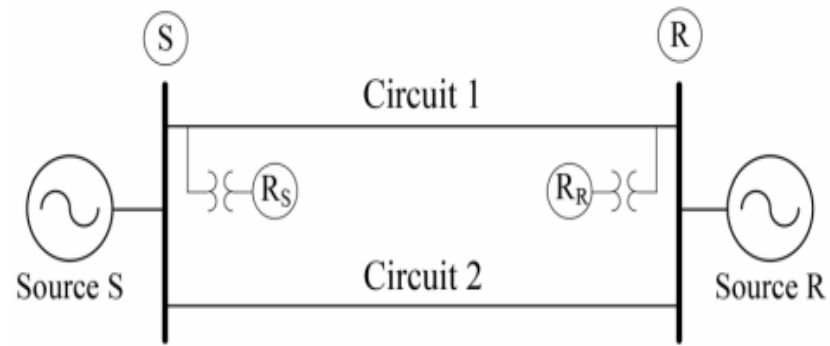

Fig.1 Double-circuit transmission line protected by the distance relays

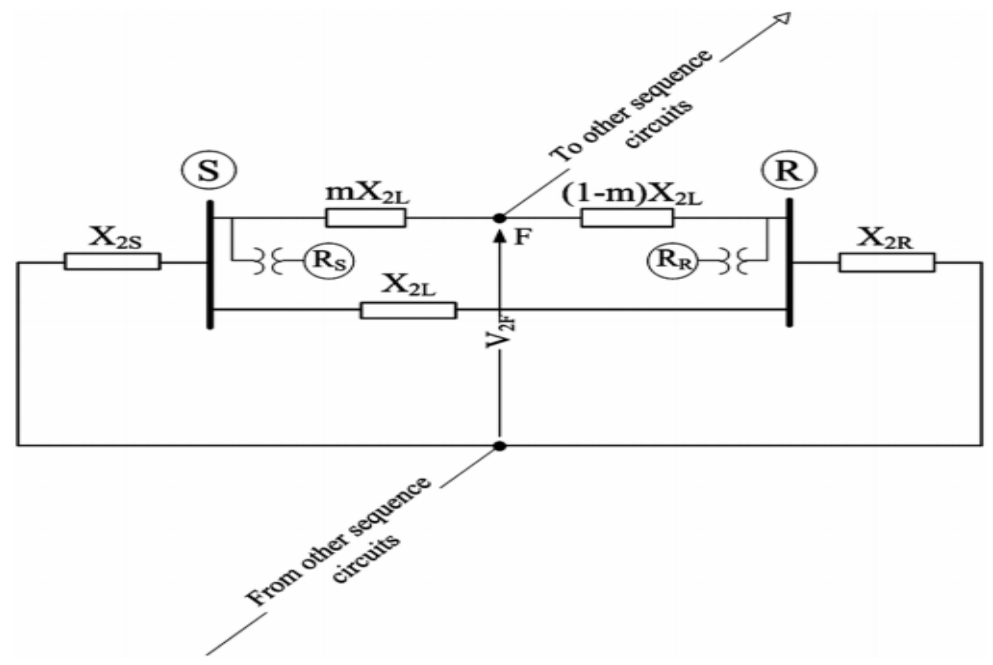

Fig.2 Negative-sequence circuit of the double-circuit transmission line for an unbalanced fault occurring at location (in per unit) from relay

The relays are fed by only voltage transformers to emphasize that the proposed method is based on only the voltage data. In transmission systems, the resistances are negligible in comparison to the reactance, and the mutual coupling between the negative-sequence components of each circuit is also negligible. If an unbalanced fault occurs at distance $\mathrm{m}$ [per unit (p.u.)] from relay in one circuit of the line, the negative-sequence circuit can thus be modelled as shown in Fig 2.

\section{DIFFERENT CASES OF FAULT LOCATION}

A double-circuit transmission line protected by distance relays shown in Fig. 1 is executed in MATLAB environment. It is applied to the test system in order to estimate the fault based on fault type and fault resistance. Different cases are involved to locate the fault in the system are considered as follows:

Case 1: Calculation of estimation errors

Case 2: Obtain sensitivity analysis

Case 3: Consideration of shunt capacitances

Case 1: Calculation of Estimation Errors

Percentage error in fault-location estimate based on the total line length: (error) $=$ (instrument reading - exact distance to the fault) divided by (total line length). 
UGC Approved Journal

IJIREEICE

\section{International Journal of Innovative Research in} Electrical, Electronics, Instrumentation and Control Engineering

\section{ISO 3297:2007 Certified}

Vol. 5, Issue 7, July 2017

$$
\text { Error } \%=\frac{\mathrm{d}-\mathrm{d}_{\text {exact }}}{\mathrm{l}} \times 100 \%
$$

Instrument reading is calculated from the data $[5 \ldots \ldots .195 \mathrm{~km}]$ Exact distance to the fault is calculated using

$$
m=\frac{2(1-k) X_{2 L} X_{2 R}+X_{2 S} X_{2 L}}{X_{2 L}\left(X_{2 S}+k X_{2 R}\right)}
$$

$\mathrm{k}$ is the ratio between the magnitudes of negative-sequence voltages at the sending $\mathrm{S}$, and receiving $\mathrm{R}$ ends of the faulted circuit. $\mathrm{m}$ is the fault location in the faulted circuit of the double circuit transmission line. Total line length $=200 \mathrm{~km}$

Table I. Different Fault Cases Considered for Evaluation Studies

\begin{tabular}{|c|l|c|c|}
\hline Case & \multicolumn{1}{|c|}{ Fault type } & Fault resistance $(\Omega)$ & Actual fault location $(\mathrm{km})$ \\
\hline 1. & $\mathrm{Ph}-\mathrm{G}$ & 50 & {$[5 \ldots 195]$} \\
\hline 2. & $\mathrm{Ph}-\mathrm{Ph}$ & 20 & every $1 \mathrm{~km}$ \\
\hline 3. & $\mathrm{Ph}-\mathrm{Ph}-\mathrm{G}$ & 100 & \\
\hline
\end{tabular}

\section{Case 2: Obtain Sensitivity Analysis}

To obtain the sensitivity analysis, the expected value of $\mathrm{k}$ (the ratio of negative-sequence voltage magnitude at the sending-end relay to the one at the receiving-end relay) is first measured while the fault location varies along the line. The sensitivity of fault location to the aforementioned parameters will be obtained as follows with the known variation of k. Taking the derivative of equation (1) in terms of $X_{2 S} \& X_{2 R}$ respectively, yields the sensitivity factor to the source reactance behind the sending-end relay as

$$
\begin{gathered}
S_{S}=\frac{X_{2 S} k X\left[2(1-k) X_{2 R}+1\right]}{m\left(X_{2 S}+k X_{2 R}\right)} \\
S_{R}=\frac{X_{2 S} k X\left[2(1-k) X_{2 R}+1\right]}{m\left(X_{2 S}+k X_{2 R}\right)}
\end{gathered}
$$

Case 3: Consideration of Shunt Capacitances

To obtain steady state results where the shunt capacitances should be considered, PI model is an absolute one. The capacitances of the healthy circuit are parallel to those of the faulted circuit at the sending and receiving ends.

\section{EVALUATION RESULTS \& DISCUSSION}

\section{A. Simulation Results}

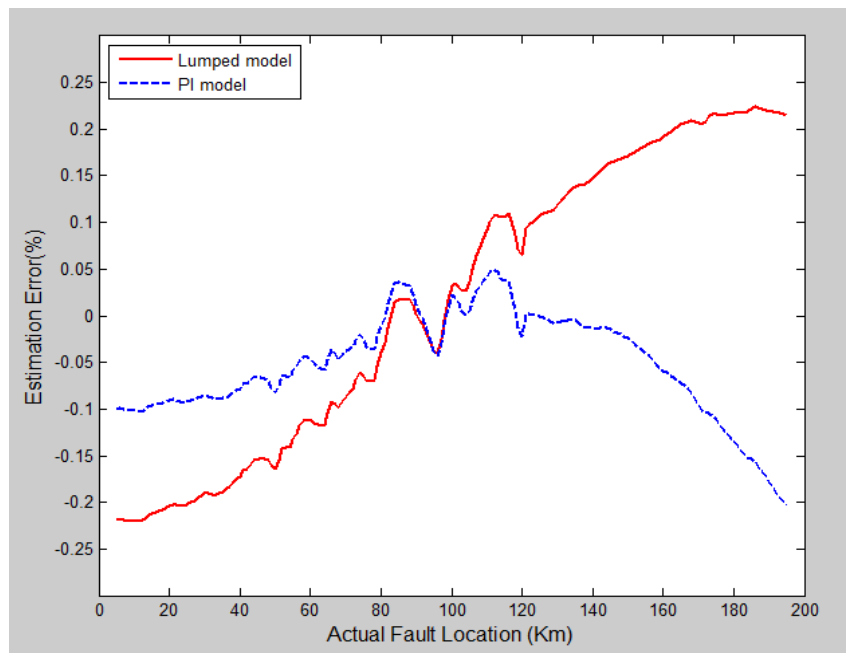

Fig.3 Ph-G Fault Type with Fault Resistance of 50ohms 
UGC Approved Journal

IJIREEICE

Vol. 5, Issue 7, July 2017

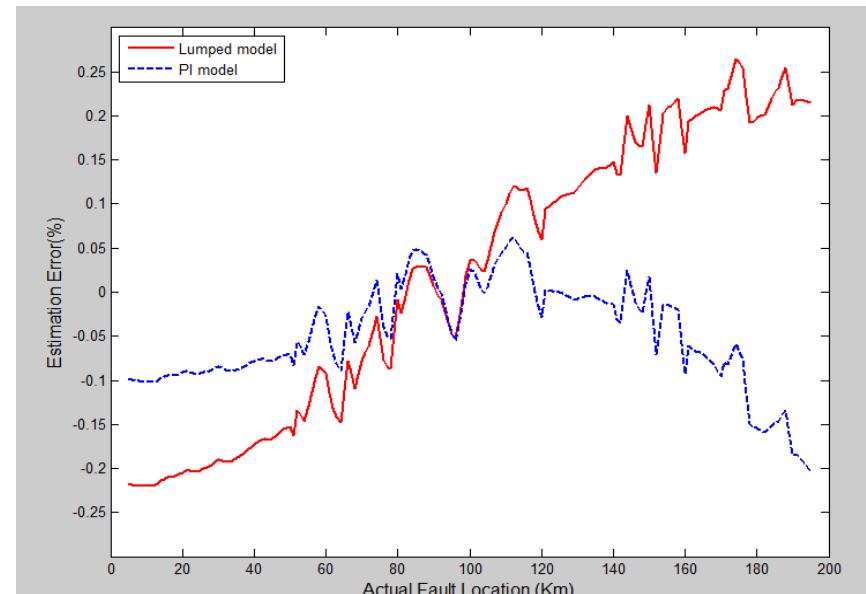

Fig.4 Ph-Ph Fault Type with Fault Resistance of 20ohms

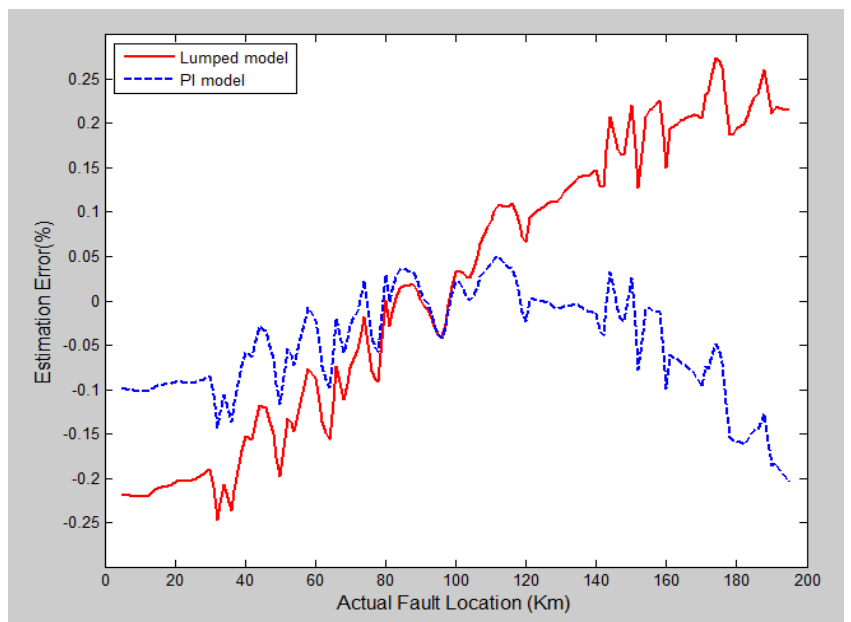

Fig.5 Ph-Ph-G Fault Type with Fault Resistance of 100 ohms

Table II Maximal \& Mean Values of Absolute Errors for each case based on the Lumped and PI Models

\begin{tabular}{|c|c|c|c|c|}
\hline \multirow{2}{*}{ Case } & \multicolumn{2}{|c|}{ Lumped Model } & \multicolumn{2}{c|}{ PI Model } \\
\cline { 2 - 5 } & Max [Error (\%)] & Mean [Error (\%)] & Max [Error (\%)] & Mean [Error (\%)] \\
\hline 1. & 0.2272 & 0.1493 & 0.2437 & 0.0886 \\
\hline 2. & 0.2399 & 0.1486 & 0.2443 & 0.0853 \\
\hline 3. & 0.2805 & 0.1466 & 0.2523 & 0.0861 \\
\hline
\end{tabular}

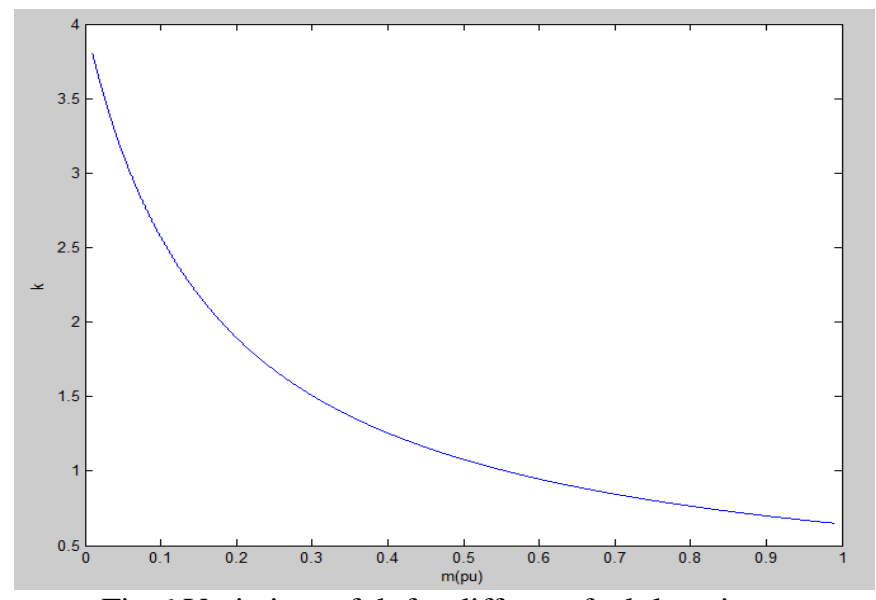

Fig.6 Variation of $\mathrm{k}$ for different fault locations 
UGC Approved Journal

IJIREEICE

\section{International Journal of Innovative Research in} Electrical, Electronics, Instrumentation and Control Engineering

\section{ISO 3297:2007 Certified}

Vol. 5, Issue 7, July 2017

Considering the table. 1 and table.2, different fault cases are considered on fault types and fault resistances. The absolute values of the estimation errors have been used to provide the maximal and mean values of the errors shown in Table II.

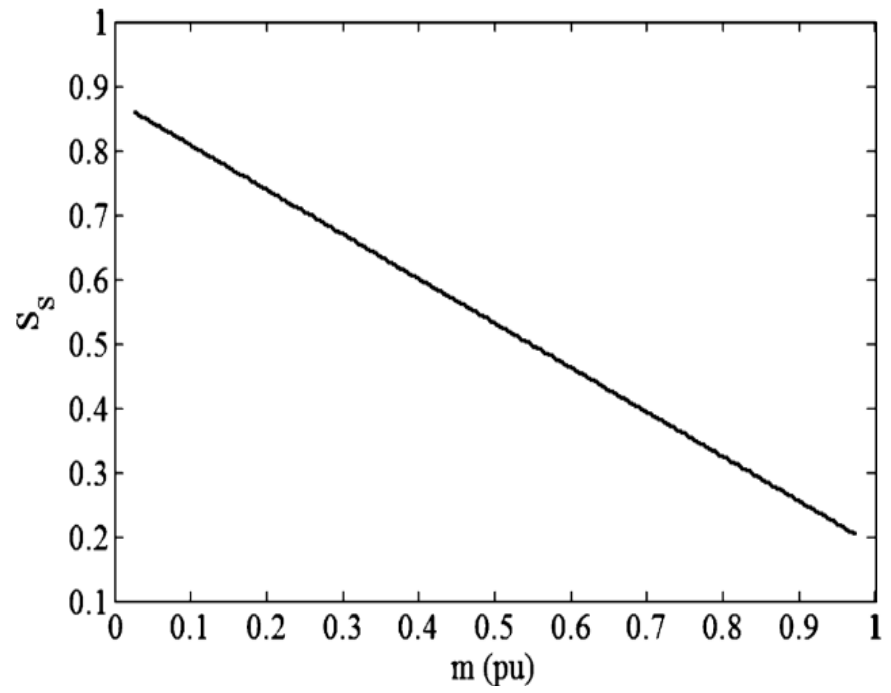

Fig. 7 Sensitivity factor to the source reactance behind the sending-end relay

The source reactances used for estimation are given either $110 \%$ or $90 \%$ of their real values.

In this sense, four possible cases for the source reactances emerged as

1) $1.1 \times X_{2 S}, 1.1 \times X_{2 R}$;

2) $0.9 \times X_{2 S}, 0.9 \times X_{2 R}$;

3) $1.1 \times X_{2 S}, 0.9 \times X_{2 R}$; and

4) $0.9 \times X_{2 S}, 1.1 \times X_{2 R}$.

As shown, even though both source reactances deviate $10 \%$ from their real values at the same time, the estimation errors still fall in a reasonable range with a maximum error of $5 \%$.

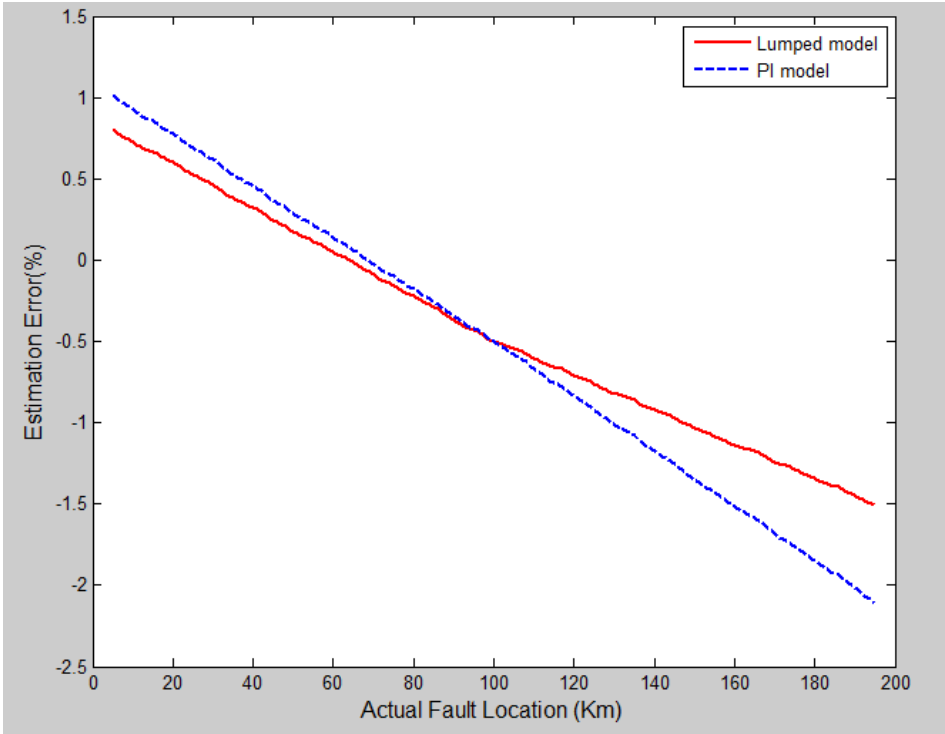

Fig.8 Estimation errors for deviation of $10 \%$ in source reactances $\left(1.1 \times \mathrm{X}_{2 \mathrm{~S}}\right.$ and $\left.1.1 \times \mathrm{X}_{2 \mathrm{R}}\right)$

These cases are based on lumped and pi model at different fault resistances and fault types. When the small difference in the estimation errors occurs then the fault type and fault resistance vary can be attributed to the errors generated by the instrument transformers (CVTs) and with numerical calculation. 
UGC Approved Journal

IJIREEICE

\section{International Journal of Innovative Research in} Electrical, Electronics, Instrumentation and Control Engineering ISO 3297:2007 Certified

Vol. 5, Issue 7, July 2017

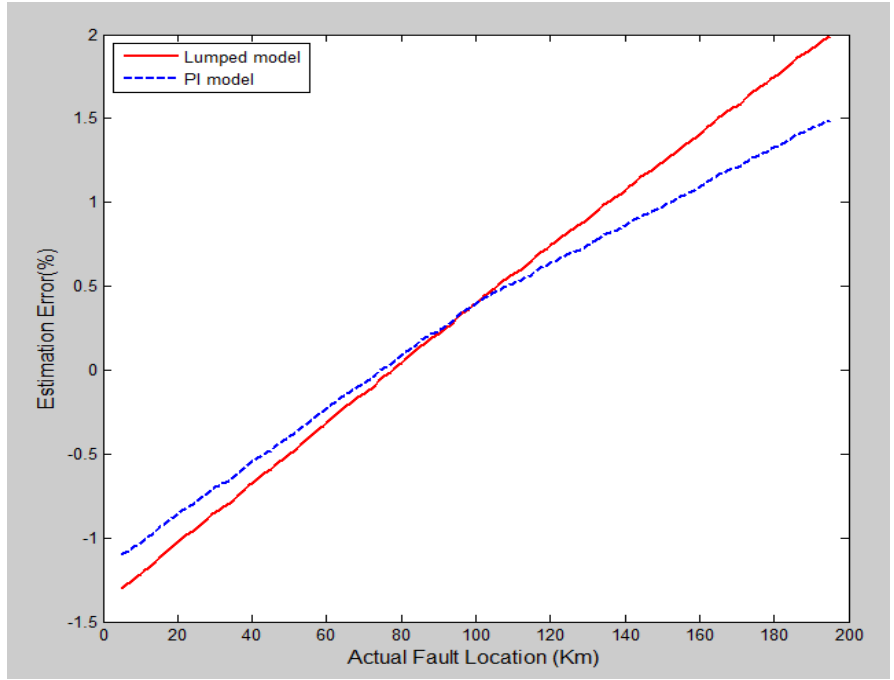

Fig.9 Estimation errors for deviation of $10 \%$ in source reactances $\left(0.9 \times X_{2 s}\right.$ and $\left.0.9 \times X_{2 R}\right)$

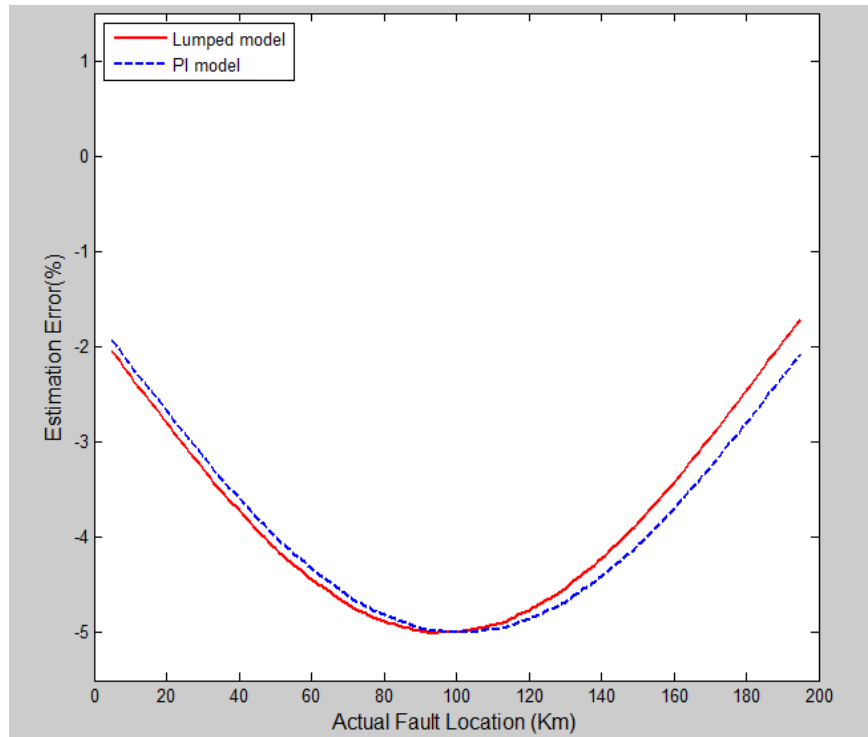

Fig.10 Estimation errors for deviation of $10 \%$ in source reactances $\left(1.1 \times \mathrm{X}_{2 \mathrm{~S}} \& 0.9 \times \mathrm{X}_{2 \mathrm{R}}\right)$

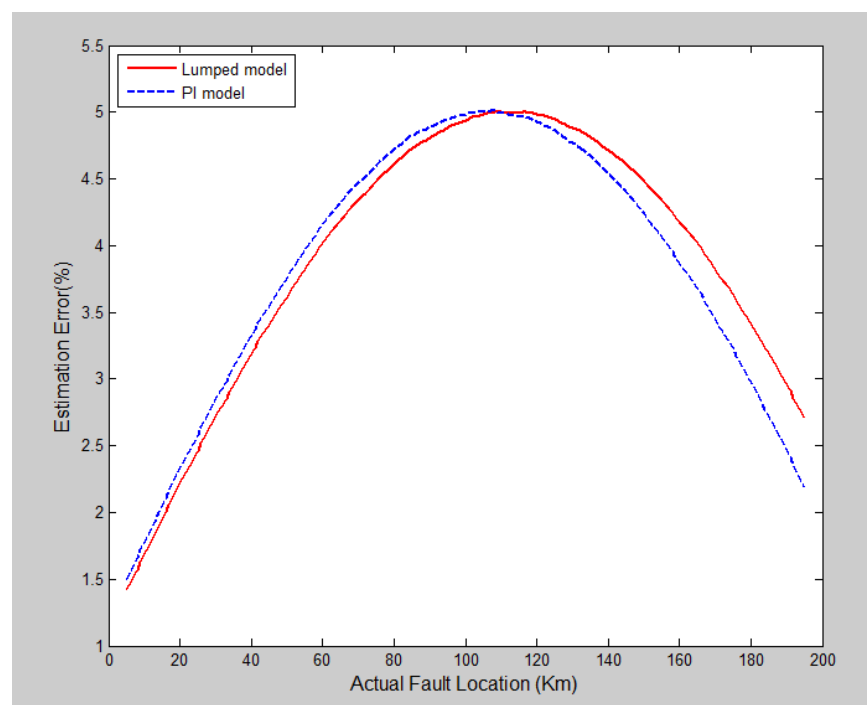

Fig.11 Estimation errors for deviation of $10 \%$ in source reactances $\left(0.9 \times \mathrm{X}_{2 \mathrm{~S}} \& 1.1 \times \mathrm{X}_{2 \mathrm{R}}\right)$ 
Vol. 5, Issue 7, July 2017

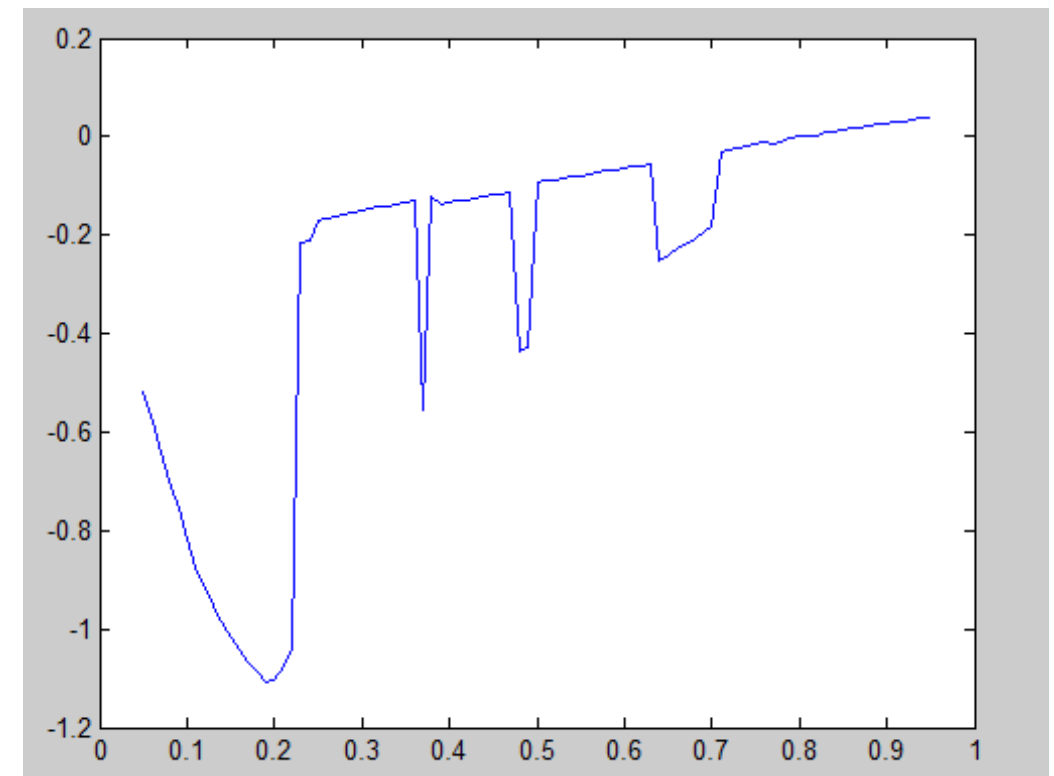

Fig.12 Curve shows that Estimation errors versus Fault location

It is shown that the accuracy of the method will be quite high and if required parameters are close enough to their real values. If fault locations are more than $0.2 \mathrm{p}$.u, then it indicates that both sensitivity factors are less than 1 which indicates a low sensitivity of the method to the variation of source reactance. At 0.3 p.u , it is calculated as 0.66 and 0.75.For given $10 \%$ tolerance, then the fault location will be estimated in the range of $[0.280,0.320]$. For $10 \%$ tolerance, then the fault location will be estimated in the range of [0.277, 0.323]. If the fault location is farther from relay, the accuracy will even be higher.

\section{CONCLUSION}

In double circuit transmission lines, locating the fault using negative sequence voltages to obtain the better accuracy even in the lumped model and in the pi model. Using the three terminal lines there is no need for fast and online data transfer and a simple low demanding low-speed communication link can be used, it provides quite satisfactory results even for long lines as the ratio between two voltage magnitudes is used.. Results shows that with three terminal lines using voltage sources improved than double circuit transmission lines.

\section{REFERENCES}

[1] T. Kawady and J. Stenzel, "A practical fault location approach for double circuit transmission lines using single end data", IEEE Trans. Power Del., vol. 18, no. 4, pp. 1166-1173, Oct. 2003.

[2] G. Song, J. Suonan, and Y. Ge, "An accurate fault location algorithm for parallel transmission lines using one-terminal data", Elect. Power Energy Syst., vol. 31, no. 2-3, pp. 124-129, 2009.

[3] J.-A. Jiang, J.-Z. Yang, Y.-H. Lin, C.-W. Liu, and J.-C. Ma, “An adaptive PMU based fault detection/location technique for transmission lines part I: Theory and algorithms”, IEEE Trans. Power Del.,vol.15, no. 2, pp. 486-493, Apr. 2000.

[4] T. Funabashi, H. Otoguro, Y. Mizuma, L. Dube, and A. Ametani, "Digital fault location for parallel double-circuit multi- terminal transmission lines", IEEE. Trans. Power. Del., vol. 15, no. 2, pp. 531-537, Apr. 2000.

[5] S. Kang, Y. Ahn, Y. Kang, and S. Nam, "A fault location algorithm based on circuit analysis for un-transposed parallel transmission lines," IEEE Trans. Power Del., vol. 24, no. 4, pp. 1850-1856, Oct. 2009.

[6] J.Izykowski, E.Rosolowski, and M.M.Saha, "Locating faults in parallel transmission lines under availability of complete measurements at one end”, Proc. Inst. Elect. Eng., Gen., Transm. Distrib., vol. 151, no. 2, pp. 268-273, Mar. 2004.

[7] N. Kang and Y . Liao, "Double-circuit transmission-line fault location utilizing synchronized current phasors", IEEE.Trans.Power.Del., vol. 28, no. 2, pp. 1040-1047, Apr. 2013.

[8] A. Apostolov, D. Tholomier, S. Sambasivan, and S. Richards, "Protection of double circuit transmission lines", presented at the 60th Annu. Conf. Protect. Relay Eng., College Station, TX, USA, Mar. 2007.

[9] G. Song, J. Suonan, Q. Xu, P. Chen, and Y. Ge, "Parallel transmission lines fault location algorithm based on differential component net," IEEE Trans. Power Del., vol. 20, no. 4, pp. 2396-2406, Oct. 2005.

[10] Y. Liao, "Fault location utilizing unsynchronized voltage measurements during fault, "Elect. Power Compon. Syst., vol.34, no.12, pp.12831293,2006 